\title{
An in-depth case study of a modular service delivery system in a logistics context
}

Article

Accepted Version

Ponsignon, F., Davies, P., Smart, A. and Maull, R. (2021) An in-depth case study of a modular service delivery system in a logistics context. International Journal of Logistics Management. ISSN 0957-4093 doi:

https://doi.org/10.1108/IJLM-07-2020-0295 Available at https://centaur.reading.ac.uk/97495/

It is advisable to refer to the publisher's version if you intend to cite from the work. See Guidance on citing.

To link to this article DOI: http://dx.doi.org/10.1108/IJLM-07-2020-0295

Publisher: Emerald

All outputs in CentAUR are protected by Intellectual Property Rights law, including copyright law. Copyright and IPR is retained by the creators or other copyright holders. Terms and conditions for use of this material are defined in the End User Agreement.

www.reading.ac.uk/centaur

\section{CentAUR}


Central Archive at the University of Reading

Reading's research outputs online 


\title{
An in-depth case study of a modular service delivery system in a logistics context
}

\begin{abstract}
Purpose: The objective of this work is to empirically investigate the design of a service delivery system that supports the provision of modular service logistics offerings.

Methodology: An in-depth single case study relying on interview data and extensive documentary evidence is carried out in the B2B logistics sector. Three main analytical techniques are used to make sense of the qualitative data: thematic analysis, process mapping and the application of modular operators.
\end{abstract}

Findings: A modular service delivery system comprises three types of processes that collectively deliver modular offerings. First, the platform consists of core processes that enable the collection, transport, and delivery of physical items for all offerings (modular and non-modular). Second, dedicated modular processes are mandatory and exclusive to individual modular offerings. Third, optional modular processes are shared across several modular offerings. Moreover, interfaces regulate physical (e.g., parcels or parts) and information (e.g., booking data) inputs provided by the customer in order to control the interdependencies within these different process types.

Practical implications: The identification of three process types and their interdependencies provides detailed insights into how managers can design modular logistics services that benefit from economies of scale and meet increasingly variable customer requirements. The importance of well-designed interfaces among the customer, the service offering, and the service delivery system is highlighted.

Originality/value: This study exends previous modularity studies in service logistics. It applies modular operators to determine the presence of modularity in the service delivery 
system and to establish the role of different process types in enabling modularity in the service delivery system.

Keywords: Logistics services, Modularity, Service Delivery System, Case Study, Modular Operators 


\section{Introduction}

Increasingly, providers of logistics services manage important portions of their customers' supply chain activities (Zacharia et al., 2011), which leads them to assume a strategic position and to be seen as core service providers (Piecyk and Björklund, 2015). The outsourcing of logistics services has thus become mainstream in the industry (Mathauer and Hofman, 2019). The worldwide market is estimated to be worth over $\$ 200$ billion and to continue to grow strongly in the coming years. ${ }^{1}$ This trend, along with heightened competitive pressures, deregulation, the rise of e-commerce, and increasingly sophisticated customer requirements, has forced logistics service firms to become more innovative (Busse and Wallenburg, 2011). Solutions have expanded beyond basic transportation and storage and include, for instance, time-critical supply and return of spare parts; the planning, implementation, and controlling of reverse logistics, as well as performance monitoring and business consulting (Selviaridis and Norrman, 2015). As noted by Hazen and Ellinger (2019), such offerings are a way to provide superior customer value and act as a competitive differentiator. However, offering bespoke solutions is cost prohibitive and likely to hinder competitiveness in the long run (Kumar and Reinartz, 2016).

Against this background, the potential benefits of modular solutions that fulfill the specific needs of individual customers in a cost-effective way has been recognised (Cabigiosu et al., 2015; Rajahonka, 2013; Yang and Lirn, 2017). Modularity provides distinct opportunities to improve operational performance and increase firm competitiveness (Baldwin and Clark, 1997; Miozzo and Grimshaw, 2005) by simultaneously allowing for the amplification of variety of the product service portfolio while attenuating variability within the operational system (Salvador et al., 2002). Amplification is achieved through the

\footnotetext{
${ }^{1}$ https://www.supplychaindive.com/news/logistics-insource-outsource/571612/
} 
configuration of modular components to meet customer requirements, enabling effectiveness. Attenuation simplifies the operational system and enables efficiency.

Scholars have claimed that "logistics services is a context with great potential for exploitation of service modularity" (Brax et al., 2017, p. 689). Modularity has a long tradition within general systems and manufacturing operations (e.g., Baldwin and Clark, 1997), but its application in service logistics is more contemporary (Lin and Pekkarinen, 2008). Although logistics services have received scholarly attention, for example Pohjosenperä et al. (2019) and Dubois et al. (2019) recently highlighted the benefits of modularity for both customisation and efficiency in the contexts of healthcare and construction logistics, the extant literature remains limited in two main aspects. First, existing studies do not directly demonstrate that modularity is actually applied. It is assumed that modularity exists with limited empirical evidence to support whether this is actually the case. Second, a detailed and comprehensive understanding of the characteristics of modularity at the operational level is missing. The objective of this work is therefore to empirically investigate the design of a service delivery system that supports the provision of modular service logistics offerings. To satisfy this objective, we seek to address the following research question: "What are the design characteristics of a service delivery system that supports modular logistics service offerings?"

The paper is structured as follows. First, we present a theoretical background that focuses on both the foundations of modularity theory and the service design literature, before integrating these bodies of knowledge with those studying modular logistics services. We then introduce our case study methodology, followed by the findings and discussion before concluding with limitations and future research directions.

\section{Theoretical Background}




\section{Foundations of modularity}

Modularization permits a degree of customer-perceived variety while controlling for cost and complexity (Starr, 2010). This is achieved through a common platform and predetermined interfaces allowing for the interchange of modules (Baldwin and Clark, 1997). The theoretical model presented in Figure 1 illustrates these concepts and their relationships. A modular system consists of a core platform $(\mathrm{P})$ that is common and mandatory. A number of modules (M) can be combined with this platform as a means to provide customization. In this case three modules are available (M1, M2, M3). The M1 module, for example, can be selected from two alternatives (M1a, M1b). The M2 module can be composed of M2a alone or can be extended to incorporate M2b. The configurations are enabled by standard interfaces both between the modules and the platform and between the modules themselves.

\section{$<$ Please insert Figure 1 about here $>$}

Building upon this generic model, extant theory incorporates modular operators (Baldwin and Clark, 2000): splitting, substituting, augmenting, excluding, inverting, and porting. Modular operators provide a robust and universally applicable approach for determining whether and how modularity is achieved in a system (Baldwin and Clark, 2000). They represent conceptual tools that help to describe the structure of modular systems and to understand how modular designs can be achieved from non-modular designs (Andriani and Carignani, 2014). Since they provide a means through which the basic patterns of system modularization can be achieved, they enable organizations to formulate modular designs relevant for their strategy and market (Baldwin and Clark, 2000). Additionally, their application allows organizations to understand how to derive different forms of economic value (Gamba et al, 2009). For example, the ability to augment a system by creating different variants of a module tailored to the needs of specific customers is a source of customer value. Similarly, porting a module 
provides organizations the opportunity to redistribute value from one system to another. These operators are defined, illustrated and explained in Table 1, building upon the generic model from Figure 1.

\section{<Please insert Table 1 about here $>$}

\section{Insights from the service design literature}

Product modularity research is focused on the characteristics of the thing that is being produced (Salvador et al., 2002), specifying how tangible components can be combined into different product configurations. This logic, however, is difficult to apply in a service context in which there is no physical product to assemble (Bask et al., 2010; Starr, 2010). Given these differences, we turn to the service management literature to provide theoretical insights into service design and modularity. Roth and Menor (2003) suggest that it is essential to consider the service offering and the service delivery system together to study service design issues. This duality perspective has garnered significant empirical support in the service operations literature (see Contiero et al., 2016; Ponsignon et al., 2011). It is also consistent with contemporary research in service logistics (Marchet et al., 2017), which explicitly identifies the offerings that are enabled through the value creation system. Specifically, congruency between these two concepts is emphasized. A service offering is developed to address the requirements of a target market, and its specifications drive the design of the service delivery system. It represents the totality of the attributes that are visible and offered to customers (Roth and Menor, 2003). These attributes include core and peripheral elements. Whilst core attributes represent the indispensable constitutive elements of the offering that satisfy the customer's primary needs, peripheral attributes are optional and supplementary to the core elements and aim to satisfy secondary needs. A service delivery system is a high-order construct that supports one or more offerings (Roth and Menor, 2003). The design of the 
service delivery system addresses the question of how the offering is delivered to customers. A total set of processes, with their associated interdependencies and resources, comprises the service delivery system (Ponsignon et al., 2011; Smart et al., 2009). These processes are combinations of tasks that rely on tangible (e.g., equipment, facilities, information systems) and intangible (e.g., skills and knowledge) resources to collectively deliver value to the end customer (Yang and Lirm, 2017).

\section{Modularity in logistics services}

The duality and congruency of service design resonate with the existing service logistics literature. In particular, Pekkarinen and Ulkuniemi (2008) propose a conceptual framework based on three dimensions. Modularity in service offerings refers to the elements or attributes that make up the solution offered to customers. For instance, national transportation is an attribute chosen by customers who need to move goods within a particular country. Process modularity represents a standardized and indivisible collection of activities that take place to produce and deliver the elements of the offering. To illustrate, a modular process may consist of the collection of activities that take place to transport goods from one place (origin) to another (destination). Modularity in organizations and networks describes how internal and external resources are loosely coordinated and coupled to support service delivery (e.g., subcontracting, shared or dedicated resources). Drawing a clear distinction between processes and internal resources is important, but, in accordance with service design theory (Ponsignon et al., 2011; Roth and Menor, 2003), the scope of service delivery system design incorporates both concepts. Follow-up research has largely built on these foundational premises, providing support for the duality and congruency of modular service offerings and service delivery system design (e.g., Bask et al., 2010; Bask et al., 2011; Cabigiosu et al., 2015; Rajahonka, 2013). Additionally, Pekkarinen and Ulkuniemi (2008) refer to the notion of interfaces, 
describing it as the management of customer contact and collaboration with customers. This suggests that interfaces are positioned at the point of interaction with specific customers.

Bask et al. (2010) refer to the service offering as a set of characteristics or functions. They define process modularity as "reusable process steps that can be combined to accomplish flexibility and customization" (p. 368). In a follow-up research, Bask et al. (2011) propose a model that delineates the modular offering (i.e., the number of variants offered to customers) from the operational activities in the modular production system. Lin and Pekkarinen (2011) inspect the characteristics of the service offering and investigate how modules can be decomposed into activities and processes. Their work describes how customer requirements may be captured and translated into specifications for developing modular services and processes. Rajahonka (2013) examine how logistics service providers perceive and use modular designs in practice. Their findings highlight that modularity is broadly applied across both service offerings and service processes. They explain that modular service offerings consist of basic attributes and add-on attributes that can be combined into a variety of forms. From a delivery perspective, they also briefly discuss the notion of platform by suggesting that "processes can be seen as modular [...] if the company has a core process, to which it combines process modules" (p. 36). Cabigiosu et al. (2015) provide an interesting empirical perspective on modular processes in third-party logistics firms. They assert that "the use of standard procedures is the constitutive element of modular services" (p. 128). They also highlight that interfaces are customer-specific (i.e., not standardized), in opposition to extant modularity theory, and enable the integration of both sets of operations (i.e., provider and customer). Rajahonka and Bask (2016) examine customer value related to the offering and the role of operational resources in supporting the delivery of customer value. They highlight the notion of commonality to describe modular service systems, whereby the same modular processes can be applied to support different variants of the modular service offering. 
Finally, the notion of customer-provided inputs (Sampson and Froehle, 2006) is emphasized as important by service modularity scholars. For instance, Avlonitis and Hsuan (2017) highlight how customers and their resources can bring variability to the system that needs to be controlled and managed with the design of appropriate interfaces. Similarly, de Blok et al. (2014) highlight that due to heterogeneous customer inputs, service interfaces need greater flexibility than those in manufacturing in order to respond to changing customer requirements over time. This evidence points to the need to explore how customer inputs are handled in a modular service delivery system (Brax et al., 2017).

There is thus an increasing corpus of knowledge exploring the relationship between modular design in both the offering and the delivery system in service logistics firms. This review identifies, however, two main gaps in this literature. First, existing studies do not directly address the question of whether modularity is actually applied in the organizations studied. Modularity is simply assumed to exist, but limited evidence is presented to empirically verify and justify this claim. To illustrate, most authors note that moving physical goods can be seen as a modular process but fail to specify in what instances it can actually be considered modular or not. Modular operators, as previously introduced, provide an opportunity to address this gap empirically and to clearly distinguish what is modular from what is not. A second gap is that existing studies offer relatively limited empirical insights into the operational capabilities that enable the provision of modular service offerings. Specifically, the characteristics of the operational system, interfaces and customer inputs are not explored in depth. For instance, no attempt is made to differentiate standardized, routinized processes that are usually found in mass service systems, which rely on welldefined formal procedures from modular processes. Additionally, the notion of a platform and its role in a modular system is largely absent from existing studies. Equally, beyond two studies (Cabigiosu et al., 2015; Pekkarinen and Ulkuniemi, 2008), the nature and role of 
interfaces in service logistics have received scant attention. Finally, limited considerations are given to the nature of customer-supplied inputs and the resulting implications for the design of modular service delivery systems. This article provides an attempt to address these gaps.

\section{Synthesis and conceptual framework}

To summarize, extant service design theory assumes a congruency of service offering and service delivery system concepts. Accordingly, service logistics studies support the notion that modularity is embodied in a firm's service offering and operational system. Studies of modularity must therefore explore this design duality, as represented in a conceptual framework (Figure 2). The service offering includes a set of basic and optional add-on attributes. The service delivery system is composed of a platform and modular processes. This conforms to the foundational premises of modularity theory. Importantly, customers are represented as suppliers providing inputs, such as their requirements (i.e., information) regarding the desired configuration of the offering and physical goods to be handled by the delivery system. Furthermore, modular operators (i.e. splitting, substituting, augmenting, excluding, inverting, and porting) are incorporated into the framework. These operators describe how systems can evolve from a non-modular to a modular design. They thus provide an opportunity to empirically identify the presence of modular designs in operational systems. Against this background, the objective of this work is to empirically investigate the design of a service delivery system that supports the provision of modular service logistics offerings. The research question is formulated as follows: What are the design characteristics of a service delivery system that supports modular logistics service offerings?

\section{Research methods}




\section{Rationale for case study research design}

The objective of this work is to empirically investigate the design of a service delivery system that enables modular offerings in a service logistics context. A single case study research design is adopted because it is suitable for supporting exploratory research focused on identifying and describing key concepts and their relationships (Voss et al., 2012). It focuses attention on the particular setting in which concepts emerge and involves gathering rich and detailed data to generate deep insights into a phenomenon (Dyer and Wilkins, 1991). Within logistics and operations management research more broadly, single case research is recognized as being useful when the aim is to generate detailed knowledge and understanding of complex phenomena that are not well understood (Gammelgaard, 2004). In addition, de Blok et al. (2014) highlight the importance of understanding the operational environment in which modularity is applied. Therefore, a single-case study provides the opportunity to study modularity within its real-life context through access to rich organizational data.

\section{Case selection}

The choice of organization was theoretically driven (Eisenhardt, 1989). Based on a review of the literature, the case organization was selected to represent (1) a provider of logistics services and (2) an organization that is explicit in its adoption of a modular logic to address the needs of the after-market supply chain. Following an online search of logistics providers in Europe and examination of their website and publicly available documents, the researchers contacted a leading logistics company that appeared to advocate modularity in its strategic intent to participate in the study. Selecting a case that explicitly addresses modularity within their operations is important and aligns with our aim of theory generation (Ketokivi and Choi, 2014). 
The case organization is a European market leader in domestic and international transportation services, and operates road and air transportation networks globally. As of 2019, the turnover amounted to c. $£ 6$ billion and 68,000 people were employed worldwide. The main division (Express), provides a range of standard domestic and international transport services. Specifically, Express delivers packages (i.e. documents, parcels, and palletized freight) on a day-definite or time-definite basis. The main operational activities involve collecting packages at a customer site, transporting them, and delivering them to a recipient, using a network of more than 2,600 facilities (e.g. warehouses, transport hubs), a fleet of about 30,000 vehicles and more than 50 aircrafts. Furthermore, the organization runs a special services $(\mathrm{SpS})$ division that provides a range of modular logistics services for business customers. At the time of the study, SpS employed about 600 people and generated about $£ 1$ billion in annual revenue. The unit of analysis is the service delivery system that supports the modular offerings of the service logistics business unit, which may use the Express network for transportation.

\section{Data collection}

A case study protocol was developed (see web appendix) to support and guide data collection and analysis. The head of operations acted as the main point of contact between the research team and the organization. Data collection involved multiple sources of information to enable data triangulation and reduce subjectivity and bias (Eisenhardt, 1989). Data sources included eight semi-structured interviews with senior employees from the marketing, innovation, and operations management departments (see Table 2). All interviews were audio-recorded and transcribed verbatim. A range of relevant documents amounting to approximately 1,000 pages was also gathered (see Table 3). 


\section{<Please insert Table 3 about here>}

\section{Data analysis}

A three-stage approach was employed to make sense of the data and derive our conclusions. In the first stage, the focus was on exploring the characteristics of the modular service offerings and the delivery system that supports them (i.e., design duality), as well as on articulating the linkages between each individual offering and its delivery mechanisms (i.e., design congruency). The objectives were (1) to define the modular service offerings and to elicit their individual attributes and (2) to develop a rich and detailed understanding of the service delivery system. Specifically, the structure and interdependencies of each concept were inspected. For the former, the analysis aimed to clearly identify the attributes and rules used to configure modular offerings. For the latter, a process lens was adopted and emphasis was placed on the pattern of tasks ${ }^{2}$ and corresponding resources (Ponsignon et al., 2011). Particular consideration was also given to the nature and role of customer inputs (Sampson and Froehle, 2006).

Interview data and documentary evidence were analyzed by using thematic coding (Flick, 2006). This involved coding the text, generating main categories from the codes, and identifying relationships between both the categories and the codes within them. Two members of the research team worked independently before coming together to discuss and agree on the outcome. Any disagreements were resolved by the inclusion of a third researcher in the process. An initial list of theory-driven thematic categories was produced, based on the case study protocol, to inform the coding task. All relevant case information was allocated to a coding category. The coded data in each category were then reviewed to inductively develop a series of additional codes that reflect the richness of the data in a more meaningful and

\footnotetext{
${ }^{2}$ Higher-order tasks are conceptualized as activities and processes.
} 
precise way. Supplementing deductive coding with inductive coding enabled the derivation of deeper empirical insights into the characteristics of the offerings and corresponding delivery mechanisms. The final coding framework is presented in the web appendix (Table A1). Particular care was taken to understand, based on interview and available flowchart documentation, the boundaries and structure of service delivery activities, the relationships between these activities, as well as the main inputs, outputs, personnel, equipment, and technology involved in performing these activities (Biazzo, 2002).

Next, the coded data was organized in a variety of data displays in the form of tables describing the structure of each individual offering and of the delivery system supporting it, to facilitate understanding and comparisons. Specifically, the data were reviewed to create empirically grounded detailed process models in order to enable further analysis using modular operators in the next stage. As noted by Aguilar-Saven (2004), process modeling enables to understand and further analyse a process. Our process models represent the structure of the entire service delivery system, that is, they identify all main process modules involved in delivering the three modular offerings as well as their interactions (i.e., how they collectively operate) (Meredith et al., 1989). In doing so, the specific processes supporting the provision of each individual attribute, as well as their order and dependence, were captured. The comparative analysis of the three detailed process models along with data displays enabled the identification of commonalities and differences in how each service offering is delivered (Miles and Huberman, 1994).

In stage two, the research drew on the work of Baldwin and Clark (2000) in order to determine the presence of modularity in the service delivery system. These authors state that "modularity is a structural fact: its existence can be determined by inspecting the structure of a particular thing" (p. 132). Specifically, the inspection of the structure of the service delivery system was guided by the characteristics of modularity as embodided by modular operators 
(Baldwin and Clark, 2000). These operators were therefore applied to the service delivery system. The process models supported structural inspection and analysis based on the modular operators. Analysis was undertaken within each pair of offering-delivery processes (similar to within-case analysis), as well as across the three pairs of offering-delivery processes (similar to cross-case analysis). The application of modular operators is illustrated graphically in Figure 3.

The final stage aimed to consolidate individual process models into an overarching conceptual framework of the service delivery system showing how the modular service offerings are supported by different process types and the interdependencies between these process types and customer-supplied inputs. Iterations were then made between empirical observations and extant theory in order to derive theoretical propositions that address the design of modular logistics services.

\section{Findings}

\section{Modular offerings}

The service logistics unit offers three modular offerings to a range of business customers from various industries.

- "Spare parts" provides replenishment of parts from global or regional warehousing managed by the case organization to maintain the uptime of customers' installed base products.

- "Centralized parts" manages the customer's inventory through centralized warehouses as well as national or regional distribution centers. The solution includes the replenishment of multiple forward stocking locations and sending parts to service vendors for use in repair. 
- "Returns" is a reverse logistics solution. It focuses on returning products from the field for repair, replacement, recycling, refurbishment, recall, or reuse, including fulfillment back to the original user.

These offerings can handle a certain level of predetermined customer input request variability. Customer requirements that fall outside the scope of these offerings are not accommodated. As illustrated in Table 4, the three service offerings have a similar structure, which includes core, extended core, and optional attributes. An innovation manager (ID 3) described this structure as follows:

There are standard services and then optional services. These ones you'll always get [i.e., core and extended core attributes] and these ones you have to tick the boxes, and there are about 12 for each value proposition [i.e., optional attributes]. We stick to the organization's nature of having the customer's requirement at its heart and having a bit of flexibility. [...] The trick is to make the customer feel like they have a bespoke solution by ticking a bunch of option boxes which actually their competitor might have also ticked.

Core attributes are common to all three offerings. This core provides basic transportation services and represents the movement of physical items from one place to another. Moreover, each offering comprises extended core attributes, which are mandatory, and optional valueadding attributes. These attributes supplement the core attributes and provide for a wide range of possible final configurations of each offering. Most extended core attributes are exclusive to an individual offering, as shown in Table 4. For instance, the "time-critical transport" attribute represents a mandatory extension to the core for the "service parts" solution. However, two common attributes are identified across the "service parts" and "centralized parts" offerings. "Outbound customer orders" and "replenishment order management" are 
mandatory extensions for both service offerings. Optional attributes provide customers with opportunities to customize each offering to meet their specific needs. As illustrated in Table 4, a majority of optional attributes (i.e., 11 out of 16) are common to two or three offerings (e.g., "order consolidation" is common to all three offerings; "pick-up drop-off collection/delivery" is common to "service parts" and "returns"). Some optional attributes (i.e., 5 out of 16) are exclusive to a specific offering (e.g., "technical courier" is available for "spare parts" only). Commonality and exclusivity of attributes within and across service offerings are determined by the underlying design rules.

\section{$<$ Please insert Table 4 about here>}

\section{Service delivery system}

\section{Overview}

The service delivery system is broken down into individual processes that collectively deliver the attributes of the service offering (Turner et al., 2004). Detailed process models illustrating how each offering is delivered, together with an application of modular operators, can be found in Figure 3. The structure (i.e., process types and their characteristics) and interdependencies (i.e., how process types connect and fit together) of the overall service delivery system are analysed further below.

\section{<Please insert Figure 3 about here >}

\section{Application of modular operators}

Core, dedicated, and optional processes are shared among service offerings to different degrees. Commonality is dependent on the final configuration of each offering, determined by the design rules associated with core and extended core attributes and the optional attributes selected by the customer. This suggests the existence of a modular structure in the service delivery system. An operations manager (ID 5) offered a general description of modular 
processes, emphasizing that the execution of all modular processes is predefined by standard operating procedures (SOPs), which are stored and managed in a central repository:

We call them modular process solutions because we do it again and again in the same way but we don't do it for $100 \%$ of the freight. Why? Because the customer is willing to pay for that. [...] When we modularize, we put it into standard operating procedures. [...]. These procedures are predeveloped and called upon whenever needed.

To appraise the presence of modularity, the structure of the entire service delivery system was inspected. This inspection was guided by the six modular operators, as illustrated in Figure 3. The analysis revealed that a range of optional attributes (e.g. "packaging", "kitting/dekitting", and "labelling") are offered by the Express division as a single integral optional package to customers. Such attributes may not be offered or delivered independently from each other and are supported by specific operational processes comprising interdependent activities. Through the application of the splitting operator, the organization has decomposing such packages into a set of distinct attributes that $\mathrm{SpS}$ customers are able to select individually according to their specific needs. Each individual attribute is supported by an independent modular process that performs a single function. Figure 3 shows how a single integral process ("handle spare parts") has been split into two optional modular processes ("package" and "label").

Moreover, extended core attributes activate mandatory dedicated processes. Inspecting these attributes (Table 4), it can be seen that the "service parts" offering has six extended core attributes. Comparing this with the "centralized parts" offering, it appears that four of these attributes have been excluded and two new extended core attributes have been augmented. This evidence suggests that the augmenting and excluding operators are applied across service offerings and delivery systems. Figure 3 shows that a dedicated process has been excluded ("create replenishment order") from the "spart parts" process model and that two dedicated 
processes have been augmented ("unload items" and "receive inbound order") to the model. In addition, evidence of an application of these operators is also found within each pair of offering-delivery processes. Specifically, for each offering, a range of optional attributes can be selected (or not) by the customer in order to generate various variants. Such attributes trigger the activation of corresponding optional processes (i.e. an augmentation of the system's capability) or the exclusion of such processes (i.e. a reduction of the system's capability). For instance, in Figure 3, an optional process ("screen item") has been added to the "returns" process model and an optional process ("label") has been removed from the model.

Further inspection of Table 4 reveals some commonality (e.g., "outbound customer orders" is available for both "service parts" and "centralized parts") and some exclusivity (e.g., "returns order management" is exclusive to "returns") across the three offerings. Three distinct sub-systems supporting each offering are identified from the high-order delivery system, which indicates the existence of separate designs, as illustrated in Figure 3. The commonality of dedicated processes across the systems delivering "spare parts" and "centralized parts" corresponds to the porting modular operator. These processes have been identified, isolated, made compatible, and moved from one system to another through the creation of a specific translator module.

Furthermore, when a customer requests an optional attribute, the entry of the order into a corresponding modular process is triggered. Within an offering, each optional process may be substituted for an alternative process that performs a different task to accommodate specific customer requirements. For example, in Figure 3, the process model for "centralized parts" shows that two modular optional processes (i.e., "screen parts" and "manage pack") can be replaced with one another. 
Finally, the platform of core processes is responsible for transporting consignments for both standard and modular offerings. This indicates that the platform is shared across both the Express and SpS divisions. Because each configuration of the $\mathrm{SpS}$ service delivery system is integrated with that of Express, the platform incorporates similar elements that are embedded in all offerings into a single set of core processes. Capturing common processes, making them visible and connecting them to other delivery processes indicates that inversion has taken place, as illustrated in Figure 3. In this case, inversion enables to share the platform across the three modular offerings.

\section{Dedicated modular processes}

Dedicated modular processes reside exclusively within the $\mathrm{SpS}$ business unit. They employ specific resources in the form of knowledge workers (e.g., order desk operator, warehouse worker, returns center worker) with high business acumen and industry knowledge and who rely, in part, on manual IT systems. These resources are not shared with the resources of the main Express business unit. Accordingly, the cost of operating dedicated modular processes is 2.5 times greater than for core processes. Additionally, key moments in dedicated processes where known break points have incurred are pinpointed. Front line operatives are empowered to act to resolve these break points in order to mitigate the impact to customer dissatisfaction and waste to the business. Expanding on the characteristics of dedicated modular processes and on their distinction from core processes, the head of operations management (ID 4) elaborated:

Special services [i.e., dedicated] processes are completely outside the core process. [...] Because of the skills, knowledge, and the ability to fire-fight and problem-solve required, you pay twice/three times the price for the person. The business acumen and industry knowledge is very high. For example, if your tablet doesn't work [...] we get 
a tablet, go to your address, and then swap. Coordinating that swap doesn't happen in the core process. What happens in the core process is [...] a delivery, [...] a collection. [...] The clever bit was done by coordinating to get a tablet from up the street to here, then putting it in the booking system as a delivery.

\section{Optional modular processes}

Optional processes provide the capability to tailor service delivery according to customer requirements without creating complex operations. They reside within and are shared with Express. The cost of operating optional modular processes is 1.5 times greater than core processes because they rely on human resources (e.g., roles, skills, and knowledge), physical resources (e.g., facilities, conveyer belts, trucks, and vans), and IT resources (e.g., SAP) that are shared with core processes (Express). Optional processes and core processes use common resources, which drive down variation and unit cost. Typically, the consignment is returned to the core process (i.e., the platform) for further processing once optional processes have been performed. An operations manager (ID 6) commented on the close relationship between optional processes and the core process, highlighting that optional processes are seen as a variation to the core, which adds customer value and incurs a cost:

The core process will not, by design, satisfy, for instance, requirements for packaging items. We train humans with skills and knowledge to recognize the exception and to do the additional activity. [...] You select whichever standard operating procedures relate to whichever optional services the customer has selected [...]. It goes across to a parallel process to do the additional value-adding activity. It means you step out of the core process; it's an exception to the core [...]. 
Core processes deal with the booking, collection, transport, and delivery of physical items. They may be enacted before or after modular processes, depending on the offering's final configuration. Core processes describe the platform that supports all the offerings of the entire organization. These processes deal with high volumes of transactions and consist of standardized sequential activities that are highly automated (e.g., conveyor belts, workflow systems), require basic employee skills and knowledge (e.g., drivers and operators), and achieve very high efficiency levels. Standard corrective action processes have been designed to deal with known exceptions such as legal constraints and discrepancies. Elaborating on the role and characteristics of the platform, an operations manager (ID 6) said:

That's a network strategy and [...] everybody's doing it on a standardized platform and a standardized way. It's the core because all the clever stuff is done by machines and we don't need to employ people with umpteen skills and knowledge on pharmaceuticals or consumer electronics; the system does it.

\section{Interfaces}

The main functions of interfaces are to manage the interdependency between the platform and dedicated modular processes and to protect the stability of the platform from undesired customer input variability. Interface rules define the conditions under which customersupplied material inputs (i.e., physical items) and information inputs (i.e., data) are accommodated or rejected by core processes. Core processes (in Express) support the transport of $70 \%$ of modular offerings; the remainder is handed over from dedicated modular processes (in $\mathrm{SpS}$ ) to third parties because parcels do not meet predetermined interface requirements (e.g., the parcel is too large). Rigid interface requirements thus dictate the range of customer inputs that the core can handle as well as how core and dedicated modular processes interact, as explained by the head of operations (ID 4): 
Special services [i.e., dedicated modular processes] have got two options. If they put the parcel across to the core network, they put it in the right box with our label on it. We go and deliver it [...]; it's just another parcel. [...]. If they give it to a third party [...], it sits in third party [...] because the input is incompatible. All those rules have been developed, recognized, and designed into the process. That's how the two models [i.e., Express and SpS] connect.

Concretely, interface rules consist of a $3 \times 3$ validation table stipulating that data, paperwork, and physical items (DPP) must be timely, accurate, and complete (TAC) to be accepted by core and optional modular processes (see Table 5). Validation takes places at each process interface. Customer booking data specifies the characteristics of the physical item to be supplied by the customer, along with appropriate paperwork (i.e., information). The interdependencies among dedicated processes, optional processes, and core processes are determined by the interfaces between these systems, as explained by an operations manager (ID 5):

DPP is the common currency from the very first touch point and all the way through. That's the only thing that's transferring across. Every time the input and the output is controlled by DPP. In SpS, the widget will trigger all the [i.e., dedicated modular] processes and at the end it's collected, transported, and delivered through the common processes.

$<$ Please insert Table 5 about here $>$

\section{Discussion}

This section synthesizes and discusses the empirical findings in the context of the existing literature. An emergent conceptual model is represented in Figure 4. Moreover, four 
theoretical propositions addressing the design of modular logistics services are formulated to structure and formalize a theoretical understanding of the phenomenon (Cornelissen, 2017).

\section{$<$ Please insert Figure 4 about here >}

A modular service logistics offering comprises core, extended core, and optional attributes that can be combined into a range of final configurations. This finding supports the view that an offering is considered modular if the customer can customize it by mixing and matching various attributes (Bask et al., 2010, 2011; Lin and Pekkarinen, 2011; Pekkarinen and Ulkuniemi, 2008; Pohjosenperä et al., 2019). Additionally, the literature asserts that a modular offering comprises a set of core attributes onto which additional optional attributes can be added (Rajahonka, 2013; Rajahonka and Bask, 2016). Our research highlights that core attributes relate to basic transportation and warehousing services (Kembro et al., 2018). They are mandatory and invariant among all final configurations of the offering. It also shows that optional attributes include traditional value-adding services that are closely related to core attributes. They can be either exclusive to individual offerings or shared by several modular offerings. Moreover, this research provides an extension to existing conceptualizations by identifying a third kind of attribute, termed extended core attributes, which refers to advanced logistics services (Selviaridis and Norrman, 2015). These attributes are mandatory and mostly exclusive to individual offerings. Extended core attributes are important because they emphasize both the specificity of a particular modular offering and its differences with other offerings. This leads to the following research proposition.

P1: Modular service logistics offerings comprise core attributes (i.e., mandatory and shared across offerings), extended core attributes (i.e., mandatory and exclusive to individual offerings), and optional attributes (i.e., exclusive or shared). 
Previous studies have conjectured that the production systems under study are modular on the basis that processes can easily be broken down into sub-processes (Rajahonka, 2013), that reusable processes can be combined with each other (Bask et al., 2010), or that the same activities are executed in many production processes (Rajahonka and Bask, 2016). These approaches appear to correspond with the splitting and substitution operators (Baldwin and Clark, 2000), sometimes referred to as commonality and combinability principles (Rajahonka, 2013; Rajahonka and Bask, 2016). However, these two operators can be applied to all systems, not just modular ones (Baldwin and Clark, 2000), making if difficult to appreciate if the interpretation of those systems as modular is valid. The present study validates the presence of modularity through the application of all modular operators.

The analysis shows that the platform comprises a set of core processes that support all modular and non-modular offerings. This is achieved through the application of the inversion modular operator (Baldwin and Clark, 2000). Moreover, modular processes are activated or deactivated according to customer requirements and the selection of particular attributes. On the one hand, the substitution modular operator (Baldwin and Clark, 2000) enables the organization to resequence optional modular processes and/or to add new optional modular processes. On the other hand, new offerings and corresponding delivery mechanisms can be determined through the exclusion and augmentation operators (Baldwin and Clark, 2000). Additionally, the identification of dedicated processes that support different modular offerings provides evidence of porting. Although exclusivity in dedicated processes allows for the provision of a range of distinct modular offerings, commonality across modular offerings enables the reuse of such processes in several systems.

Furthermore, data analysis enables the development of a robust understanding of the modular service delivery system. Importantly, the three process types exhibit different operational characteristics and degrees of reusability across the modular offerings. Core 
processes collect, transport, and delive physical items for all the offerings of the organization. This part of the system is highly automated, efficient, and stable over time. It resonates with the concept of a technical core (Thompson, 967) and with the concept of the logistics factory as value-creation system (Prockl et al., 2012). Core processes are used for a majority of service logistics customers, except those not conforming to interface rules. This resonates with several authors (e.g., Rajahonka, 2013; Rajahonka and Bask, 2016) who find that commonality in service production is a key dimension of a modular design. This research extends this view by showing that commonality is enabled by a platform of core processes. Maximizing platform reuse therefore supports efficiency within the delivery system, enabling service logistics firms dealing with high volumes of transactions to target economies of scale (Prockl et al., 2012).

Next, dedicated and optional modular processes are focused on extended core and optional attributes. These processes are combined with each other as well as with the platform in a variety of ways to deliver modular offerings. This finding supports the work of Rajahonka (2013), who previously established that service logistics companies operate a core process to which process modules can be combined. It also provides an extension to this work by identifying and characterizing two types of modular processes. Both sets of modular processes are formalized, well-defined, and their execution is entirely predetermined in standard operating procedures. However, optional processes share the same pool of lowskilled human resources and automated activities as the platform. By contrast, dedicated processes rely on their own transforming resources, which exhibit characteristics of knowledge workers and are significantly more costly. They fit the description of the lernstatt delivery system, which relies on know-how and supports the delivery of innovative offerings (Prockl et al., 2012). Taken collectively, these findings strongly resonate with Cabigiosu et al. (2015), who differentiate standard modular processes, which rely on standard operating 
procedures and use shared resources, from customized modular processes that use dedicated transforming resources. On that basis, this research suggests that, on the one hand, delivering modular offerings that share common dedicated processes enables the achievement of economies of scope. On the other hand, reusing optional processes across multiple modular offerings enables meeting a range of customer requirements without compromising operational efficiency. This leads to the two following propositions:

P2: The greater the degree of reuse of dedicated processes among multiple modular offerings, the greater the levels of efficiency that the service delivery system can achieve through economies of scope.

P3: The greater the degree of reuse of optional processes among multiple modular offerings, the greater the degree of perceived customization that can be achieved while maintaining service delivery system efficiency.

Last, the findings explain the dual role played by interfaces in managing customer input variability, as well as in connecting core and modular processes together. The data support the well-accepted view that managing input variability is a key challenge because customer requirements and physical items vary dramatically from customer to customer (Sampson and Froehle, 2006). The role of interfaces is to determine whether customer-supplied inputs are accepted or rejected by the system. At the offering level, customer requirements are channeled through the structure of the modular offerings, specifying what attributes are available for the customer to choose. Requirements that fall outside these parameters are not accommodated. On the service delivery level, interfaces regulate physical (e.g., parcels or parts) and information (e.g., booking data) inputs in order to control the interdependencies within different process types. In particular, interfaces protect the stability of the platform by 
accommodating an array of predetermined inputs and by routing those that fall outside out to third-party service providers. In other words, interfaces provide a mechanism that protects the technical core of the organization (Thompson, 1967) from inappropriate or inadequate customer inputs (Frei, 2007). This perspective supports and extends previous work (e.g., Pekkarinen and Ulkuniemi, 2008) that suggests that interfaces in a modular service logistics system are positioned at the point of customer need identification. Our study shows that the characteristics of the customer inputs supplied both at the offering level (i.e., customer requirements) and at the service delivery system level (i.e., physical items) are important. In accordance with mainstream modularity literature, interface requirements were found to be predefined in order to control input variability. In addition, there is support for Cabigiosu et al. (2015), who argue that customer-specific (i.e., not standardized) interfaces are often required to provide modular services. In our case study, the interface linking customersupplied physical items and dedicated modular processes is also specific to individual customers. However, this is only a partial view of the overall service delivery system. Standard interfaces are essential to determine whether or not physical items may be transferred from dedicated to core processes for transportation and delivery. Thus, standard interfaces render core, optional, and dedicated processes compatible with each other by specifying what can and cannot flow across them. This finding provides an extension to Rajahonka's (2013) work, which found that standard interfaces enable the functioning of different process modules, but did not provide further explanation regarding the nature of these interfaces. The final proposition is formulated as follows:

P4: Interfaces protect the efficiency of the platform by rejecting customer-supplied inputs (i.e., information and physical items) that do not meet predetermined standardized rules. 


\section{Conclusions}

This article's main contribution is to advance theoretical understanding of modularity in a service logistics context. Specifically, modular operators are applied to identify the existence of modularity in a service delivery system. Moreover, the research provides empirical evidence of the design characteristics of a modular service delivery system. Our emergent conceptual model (Figure 4) shows that a platform of core processes is identified along with interfaces that control customer input variability and enable integration with dedicated and optional modular processes. Theoretical propositions addressing the design of modular logistics services have been formulated to structure and formalise these empirical findings.

By understanding modularity at the operational level, insights that are useful to practicing managers seeking to develop modular solutions for increasingly complex logistics operations can be generated. Notably, two main managerial implications are proposed. First, by providing an in-depth analysis of a leading logistics organization, this research provides a novel insight into (1) the structural design of a modular service delivery systems (i.e., the types of process [core, extended core, and optional] and their characteristics) and (2) the interdependencies among them (i.e., how they connect and communicate with one another) through the application and evaluation of the modular operators. The identification of how these three process types and the interdependencies between them were created provides a detailed insight into how managers can design modular logistics services that benefit from economies of scale (i.e., efficiency) and meet increasingly variable customer requirements (i.e., effectiveness). Second, this research highlights the importance of well-designed interfaces among the customer, the service offering, and the service delivery system. Specifically, the findings highlight the need to provide a rigid specification of required inputs from the customer, for both information (i.e., requirements and booking data) and physical possessions (i.e., parcels), to ensure compatibility between customer-supplied inputs at the 
service offering level and the capabilities at the service delivery system level. Should the customer-supplied inputs not conform with the interface specifications, managers need to consider rejecting these to protect the efficiency of the wider service delivery system. To avoid rejection when possible and serve the customer efficiently, the findings bring to the fore the need for managers to understand the customer-supplied inputs and design appropriate interfaces to manage the variety provided by them.

This research has several limitations that open up opportunities for future research. First, the study is positioned as an exploratory piece of research. Because the study is descriptive rather than prescriptive, it is difficult to infer design principles for service modularity. Although the focal business unit was profitable at the time of the study, the consequences of service modularity on performance are not directly considered. Second, further empirical developments are necessary to explore the applicability and transferability of the conceptual model in different settings within and outside service logistics. A multiple case study design could be used to provide further validity. Third, this article adopts a providercentric perspective to explore the modularity phenomenon. The implications of modularity from the perspective of customers are not taken into account. Exploring the perceptions of customers who buy and use modular logistics services represent a fruitful avenue for future research. Fourth, this study provides support for the view that modularity logic is a viable approach to meet the requirements of multiple customers while simultaneously minimizing complexity and cost. In addition to economic performance, logistics firms are increasingly focused on minimizing the environmental impact of their activities. Future research could explore if and how the implementation of modularity principles plays a role in influencing the social, societal, and environmental dimensions of the performance of logistics firms.

More generally, given the relative immaturity of modularity theory in the service logistics context (Brax et al, 2017), this case study forms an important step in delineating a 
theoretical understanding of the phenomenon and in serving as a stepping stone for further research. We hope that it will acts as a driver for the development of rich qualitative case studys and subsequently of hypothetico-deductive survey-based research to examine the characteristics and performance implications of service modularity. We wholeheartedly encourage logistics scholars to actively seek and seize opportunities for conceptual and empirical research in this high-potential but still relatively uncharted area. 


\section{REFERENCES}

Andriani, P., \& Carignani, G. (2014), "Modular exaptation: A missing link in the synthesis of artificial form", Research Policy, Vol. 43 No. 9, pp. 1608-1620.

Aguilar-Saven, R.S. (2004), "Business process modelling: Review and framework", International Journal of production economics, Vol. 90 No. 2, pp. 129-149.

Avlonitis, V. and Hsuan, J. (2017), “Exploring modularity in services: Cases from tourism”, International Journal of Operations \& Production Management, Vol. 37 No. 6, pp. $771-790$.

Baldwin, C.Y. and Clark, K.B. (1997), "Managing in an age of modularity", Harvard Business Review, Vol. 75 No. 5, pp. 84-93.

Baldwin, C.Y. and Clark, K.B. (2000), Design Rules, MIT Press, Cambridge, MA.

Bask, A., Lipponen, M., Rajahonka, M. and Tinnilä, M. (2010), "The concept of modularity: Diffusion from manufacturing to service production", Journal of Manufacturing Technology Management, Vol. 21 No. 3, pp. 355-375.

Bask, A., Lipponen, M., Rajahonka, M. and Tinnilä, M. (2011), "Framework for modularity and customization: Service perspective", The Journal of Business and Industrial Marketing, Vol. 26 No. 5, pp. 306-319.

Biazzo, S. (2002), "Process mapping techniques and organisational analysis: Lessons from sociotechnical system theory", Business Process Management Journal, Vol. 8 No. 1, pp. $42-52$.

Brax, S.A., Bask, A., Hsuan, J. and Voss, C. (2017), "Service modularity and architecturean overview and research agenda", International Journal of Operations \& Production Management, Vol. 37 No. 6, pp. 686-702. 
Busse, C. and Wallenburg, C.M. (2011), "Innovation management of logistics service providers: Foundations, review, and research agenda", International Journal of Physical Distribution \& Logistics Management, Vol. 41 No. 2, pp.187-218.

Cabigiosu, A., Campagnolo, D., Furlan, A. and Costa, G. (2015), "Modularity in KIBS: The case of third-party logistics service providers", Industry and Innovation, Vol. 22 No. 2, pp. 126-146.

Contiero, E., Ponsignon, F., Smart, P. and Vinelli, A. (2016), "Contingencies and characteristics of service recovery system design: Insights from retail banking", International Journal of Operations \& Production Management, Vol. 36 No. 11, pp. $1644-1667$.

Cornelissen, J. (2017), "Editors comments: Developing propositions, a process model, or a typology? Addressing the challenges of writing theory without a boilerplate", Academy of Management Review, Vol. 42, pp. 1-9.

de Blok, C., Meijboom, B., Luijkx, K., Schols, J. and Schroeder, R. (2014), "Interfaces in service modularity: A typology developed in modular health care provision", Journal of Operations Management, Vol. 32 No. 4, pp. 175-189.

Dubois, A., Hulthén, K., and Sundquist, V. (2019). “Organising logistics and transport activities in construction", The International Journal of Logistics Management, Vol. 30 No. 2, pp. 620-640.

Dyer, W. G., Jr. and A. L. Wilkins (1991), "Better Stories, Not Better Constructs, to Generate Better Theory: A Rejoinder to Eisenhardt", Academy of Management Review, Vol. 16 No. 3, pp. 613-619.

Eisenhardt, K.M. (1989), "Building theories from case study research", Academy of Management Review, Vol. 14 No. 4, pp. 532-550.

Flick, U. (2006), An Introduction to Qualitative Research, London, Sage. 
Frei, F.X. (2007), "Breaking the trade-off between efficiency and service", Harvard Business Review, Vol. 85 No. 3, pp. 93-101.

Gamba, A. and Fusari N. (2009), "Valuing modularity as a real option”, Management science, Vol. 55 No. 11, pp. 1877-1896.

Gammelgaard, B. (2004), "Schools in logistics research? A methodological framework for analysis of the discipline”, International Journal of Physical Distribution \& Logistics Management, Vol. 34 No. 6, pp. 479-91.

Hazen, B. and Ellinger, A. (2019), "Special issue editorial: Logistics customer service revisited", International Journal of Physical Distribution \& Logistics Management, Vol. 49 No. 1, pp. 2-3.

Ketokivi, M., \& Choi, T. (2014). "Renaissance of case research as a scientific method", Journal of Operations Management, Vol. 32 No. 5, pp. 232-240.

Kembro, J., Norrman, A. and Eriksson, E. (2018), "Adapting warehouse operations and design to omni-channel logistics: A literature review and research agenda", International Journal of Physical Distribution \& Logistics Management, Vol. 48 No. 9, pp. 890-912.

Kumar, V. and Reinartz, W. (2016), “Creating enduring customer value”, Journal of Marketing, Vol. 80 (November), pp. 36-68.

Lin, Y. and Pekkarinen, S. (2011), "QFD-based modular logistics service design", The Journal of Business and Industrial Marketing, Vol. 26 No. 5, pp. 344-356.

Marchet, G., Melacini, M., Perotti, S., Sassi, C. and Tappia, E. (2017), "Value creation models in the 3PL industry: what 3PL providers do to cope with shipper requirements", International Journal of Physical Distribution \& Logistics Management, Vol. 47 No. 6, pp. 472-494. 
Mathauer, M. and Hofman, E. (2019), “Technology adoption by logistics service providers”, International Journal of Physical Distribution and Logistics Management, Vol. 49. No. 4, pp. 416-434.

Meredith, J.R., Raturi, A., Amoako-Gyampah, K. and Kaplan, B. (1989), “Alternative research paradigms in operations", Journal of Operations Management, Vol. 8 No. 4, pp. 297-326.

Miles, M.B. and Huberman, M. (1994), Qualitative Data Analysis: An Expanded Sourcebook, Sage, Newbury Park, CA.

Miozzo, M. and Grimshaw, D. (2005), "Modularity and innovation in knowledge-intensive business services: IT outsourcing in Germany and the UK", Research Policy, Vol. 34 No. 9, pp. 1419-1439.

Pekkarinen, S. and Ulkuniemi, P. (2008), "Modularity in developing business services by platform approach", The International Journal of Logistics Management, Vol. 19 No. 1, pp. 84-103.

Piecyk, M.I. and Björklund, M. (2015), "Logistics service providers and corporate social responsibility sustainability reporting in the logistics industry", International Journal of Physical Distribution \& Logistics Management, Vol. 45 No. 5, 459-485.

Pohjosenperä, T., Kekkonen, P., Pekkarinen, S. and Juga, J. (2019), “Service modularity in managing healthcare logistics”, The International Journal of Logistics Management, Vol. 30 No. 1, pp. 174-194.

Ponsignon, F., Smart, P.A. and Maull, R.S. (2011), "Service delivery system design: Characteristics and contingencies", International Journal of Operations \& Production Management, Vol. 31 No. 3, pp. 324-349. 
Prockl, G., Pflaum, A. and Herbert, K. (2012), “3PL factories or lernstatts? Value-creation models for3PL service providers", International Journal of Physical Distribution and Logistics Management, Vol. 42 No. 6, pp. 544-561.

Rajahonka, M. (2013), "Views of logistics service providers on modularity in logistics services", International Journal of Logistics Research and Applications, Vol. 16 No. 1, pp. 34-50.

Rajahonka, M. and Bask, A. (2016), "The development of outbound logistics services in the automotive industry: A logistics service provider's view”, The International Journal of Logistics Management, Vol. 27 No. 3, pp. 707-737.

Roth, A.V. and Menor, L.J. (2003), "Insights into service operations management: A research agenda", Production \& Operations Management, Vol. 12 No. 2, pp. 145-164.

Salvador, F., Forza, C. and Rungtusanatham, M. (2002), "Modularity, product variety, production volume, and component sourcing: Theorizing beyond generic prescriptions", Journal of Operations Management, Vol. 20 No. 5, pp. 549-575.

Sampson, S.E. and Froehle, C.M. (2006), "Foundations and implications of a proposed unified services theory", Production \& Operations Management, Vol. 15 No. 2, pp. $329-343$.

Selviaridis, K. and Norrman, A. (2015), "Performance-based contracting for advanced logistics services: Challenges in its adoption, design and management", International Journal of Physical Distribution \& Logistics Management, Vol. 45 No. 6, pp. 592617.

Starr, M.K. (2010), "Modular production: A 45-year-old concept", International Journal of Operations \& Production Management, Vol. 30 No. 1, pp. 7-19.

Thompson, J.D. (1967), Organizations in Action, McGraw-Hill, New York, NY. 
Turner, T., Martinez, V. and Bititci, U. (2004), "Managing the value delivery process", International Journal of Physical Distribution \& Logistics Management, Vol. 34 No. 3/4, pp. 302-318.

Voss, C., Tsikriktsis, N. and Frohlich, M. (2002), "Case research in operations management", International Journal of Operations \& Production Management, Vol. 22 No. 2, pp. $195-219$.

Yang, C. and Lirn, T. (2017), "Revisiting the resource-based view on logistics performance in the shipping industry", International Journal of Physical Distribution \& Logistics Management, Vol. 47 No. 9, pp. 884-905.

Zacharia, Z.G., Sanders, N.R. and Nix, N.W. (2011), "The emerging role of the third-party logistics provider (3PL) as a supply chain orchestrator", Journal of Business Logistics, Vol. 32 No. 1, pp. 40-54. 
Table 1: Modular Operators (adapted from Baldwin and Clark, 2000).

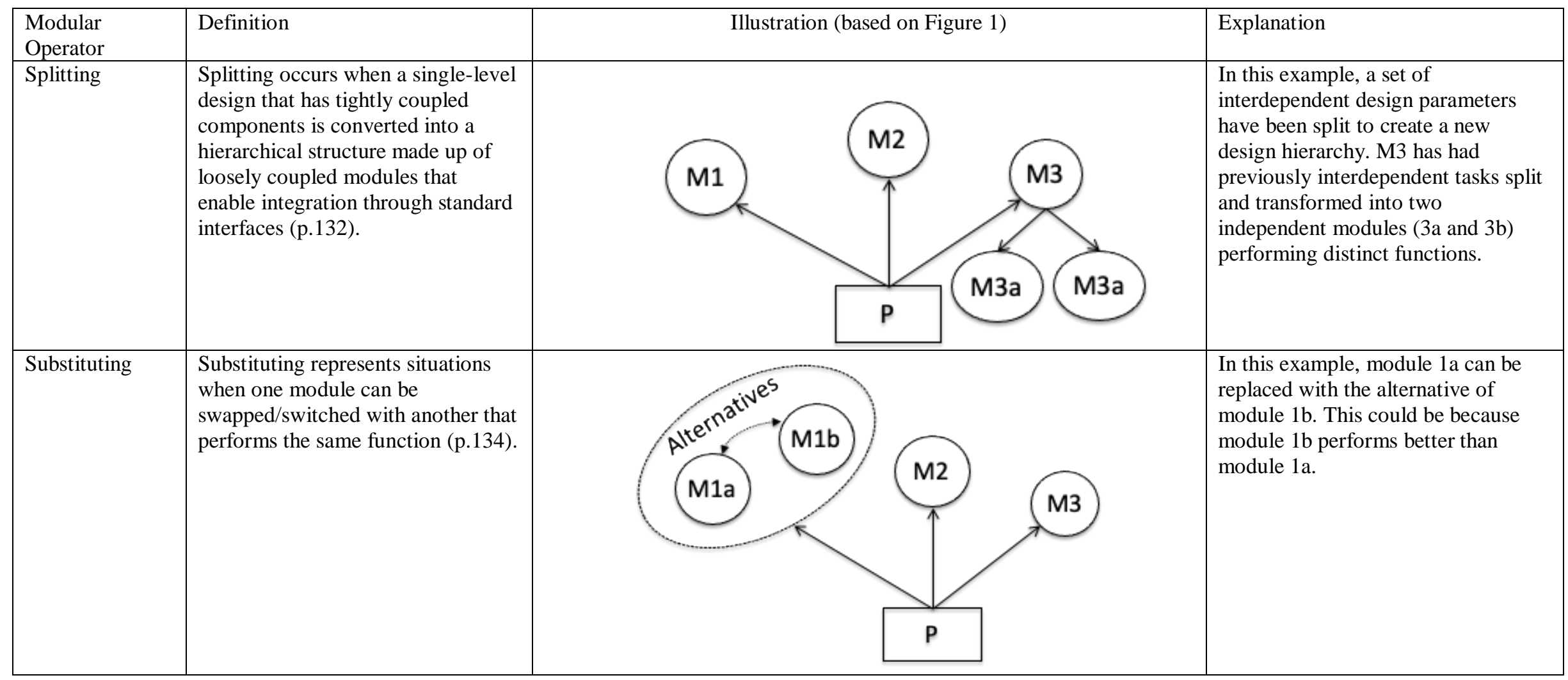




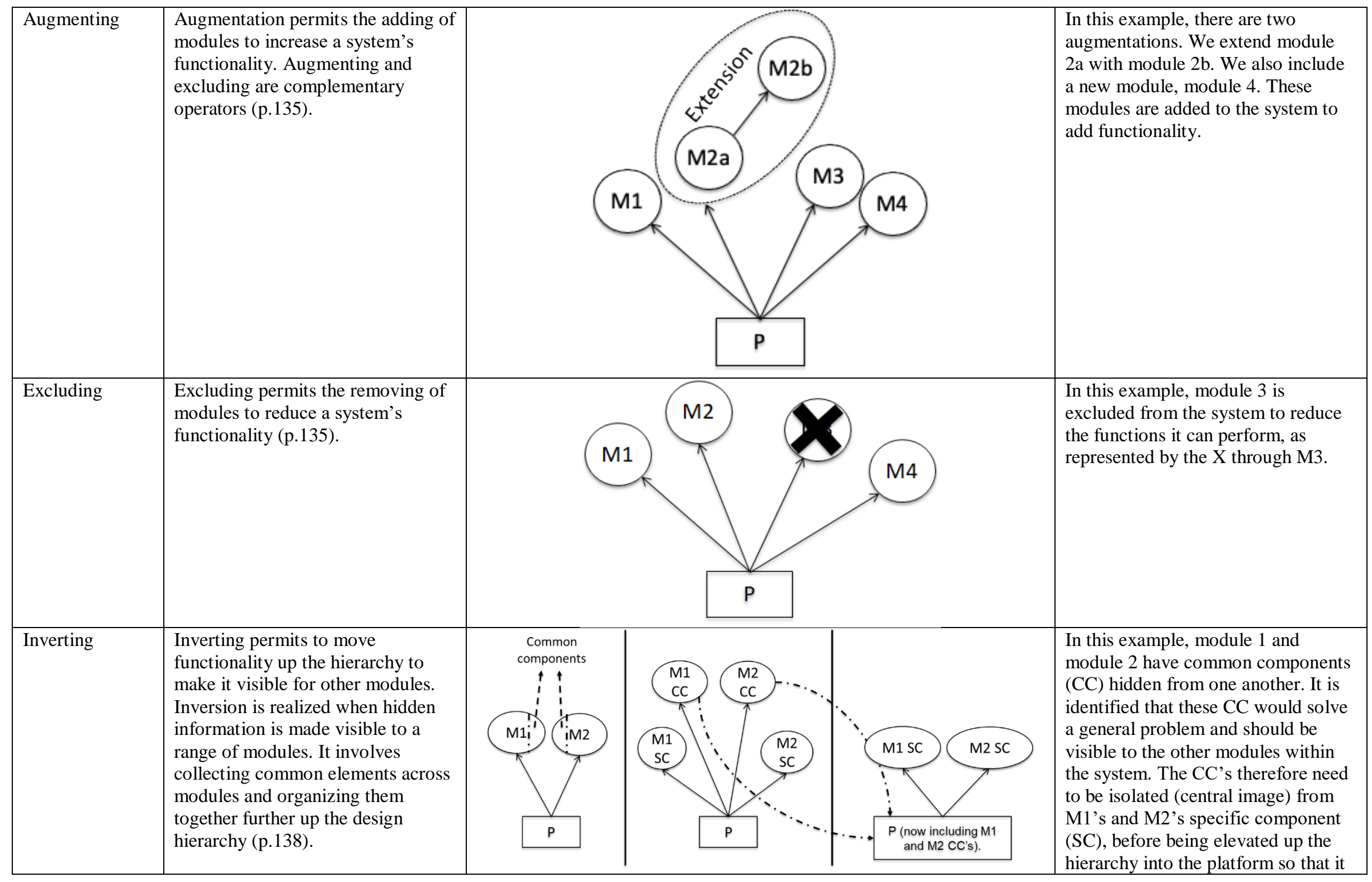




\begin{tabular}{|l|l|l|l|l}
\hline & & $\begin{array}{l}\text { is visible for other modules in the } \\
\text { system. The module CC's are now } \\
\text { part of the platform. }\end{array}$ \\
\hline Porting & $\begin{array}{l}\text { Porting represents a situation where } \\
\text { a module is able to function in more } \\
\text { than one system (under different } \\
\text { design rules). For instance, a } \\
\text { previously hidden module can be } \\
\text { moved from one system to another } \\
\text { (p.140). }\end{array}$
\end{tabular}


Table 2: Characteristics of key informants

\begin{tabular}{|c|l|c|}
\hline ID & \multicolumn{1}{|c|}{$\begin{array}{c}\text { Participant background } \\
\text { (job title, function) }\end{array}$} & $\begin{array}{c}\text { Total interview } \\
\text { duration }\end{array}$ \\
\hline 1 & Manager, marketing & $1 \mathrm{~h} 30$ \\
\hline 2 & Manager, innovation & $1 \mathrm{~h} 50$ \\
\hline 3 & Manager, innovation & $1 \mathrm{~h} 45$ \\
\hline 4 & Head of department, operations & $5 \mathrm{~h} 55$ \\
\hline 5 & Manager, operations & $1 \mathrm{~h} 35$ \\
\hline 6 & Manager, operations & $1 \mathrm{~h} 45$ \\
\hline
\end{tabular}


Table 3: Documentary evidence

\begin{tabular}{|c|c|c|c|}
\hline Functional area & Description & Type & Length \\
\hline Marketing & $\begin{array}{l}\text { Service logistics - Centralized parts } \\
\text { Service logistics - Service parts } \\
\text { Service logistics - Returns } \\
\text { Successful customer outcome }\end{array}$ & $\begin{array}{l}\text { Brochure } \\
\text { Brochure } \\
\text { Brochure } \\
\text { Report }\end{array}$ & $\begin{array}{l}5 \text { pages } \\
5 \text { pages } \\
5 \text { pages } \\
1 \text { page } \\
\end{array}$ \\
\hline Operations & $\begin{array}{l}\text { SpS assessment templates } \\
\text { SpS assessment sign-off } \\
\text { SpS assessment action plan } \\
\text { SpS assessment checklists } \\
\text { Service logistics process models } \\
\text { (high-level) } \\
\text { Service logistics process flowcharts } \\
\text { (low-level) } \\
\text { SpS assessment report } \\
\text { Service logistics operational } \\
\text { readiness assessment } \\
\text { Service logistics readiness } \\
\text { assessment } \\
\text { Process diagnostic workshop } \\
\text { End-to-end process for 'handling } \\
\text { returns' (high-level) } \\
\text { Process excellence - next steps } \\
\text { Process mapping (Express): } \\
\text { methodology, description and } \\
\text { models } \\
\text { Process architecture (Express and } \\
\text { SpS) }\end{array}$ & $\begin{array}{l}\text { Spreadsheets } \\
\text { Report } \\
\text { Report } \\
\text { Report } \\
\text { Report } \\
\text { Flowcharts } \\
\text { Report } \\
\text { Presentation } \\
\text { Presentation } \\
\text { Presentation } \\
\text { Flowchart } \\
\text { Report } \\
\text { Report and flowcharts } \\
\text { Presentation }\end{array}$ & $\begin{array}{l}27 \text { sheets } \\
3 \text { pages } \\
10 \text { pages } \\
1 \text { page } \\
15 \text { pages } \\
34 \text { models } \\
380 \text { pages } \\
37 \text { slides } \\
32 \text { slides } \\
26 \text { slides } \\
1 \text { model } \\
19 \text { pages } \\
493 \text { pages } \\
2 \text { slides }\end{array}$ \\
\hline Innovation & Innovation process & Presentation & 7 slides \\
\hline
\end{tabular}


Table 4: The structure of modular service logistics offerings

\begin{tabular}{|c|c|c|c|c|}
\hline \multirow[t]{2}{*}{ Attribute type } & \multirow{2}{*}{ Attribute } & \multicolumn{3}{|c|}{ Service offering } \\
\hline & & Service parts & $\begin{array}{c}\text { Centralized } \\
\text { parts }\end{array}$ & Returns \\
\hline Core & $\begin{array}{l}\text { Domestic transport } \\
\text { International transport }\end{array}$ & $\begin{array}{l}\mathrm{X} \\
\mathrm{X}\end{array}$ & $\begin{array}{l}X \\
X\end{array}$ & $\begin{array}{l}\mathrm{X} \\
\mathrm{X}\end{array}$ \\
\hline Extended core & $\begin{array}{l}\text { Time critical transport } \\
\text { Defective stock returns } \\
\text { Outbound customer orders } \\
\text { Replenishment order management } \\
\text { Order handling } \\
\text { Forward stocking locations } \\
\text { Customs clearance } \\
\text { Non-time-critical parts orders } \\
\text { Consumer deliveries } \\
\text { Consumer pickups } \\
\text { Postal returns } \\
\text { Swap options } \\
\text { Returns order management }\end{array}$ & $\begin{array}{l}\mathrm{X} \\
\mathrm{X} \\
\mathrm{X} \\
\mathrm{X} \\
\mathrm{X} \\
\mathrm{X}\end{array}$ & $\begin{array}{l}X \\
X \\
X \\
X\end{array}$ & $\begin{array}{l}X \\
X \\
X \\
X \\
X\end{array}$ \\
\hline Optional & $\begin{array}{l}\text { Pick-up drop-off collection/delivery } \\
\text { Packaging } \\
\text { Dedicated customer transport solution } \\
\text { Order consolidation } \\
\text { Customer labelling } \\
\text { Kitting/dekitting } \\
\text { Same time swap } \\
\text { Technical courier } \\
\text { Outbound order desk management } \\
\text { Physical screening } \\
\text { Returns order desk management } \\
\text { Pack management } \\
\text { Packaging fulfillment } \\
\text { Screening } \\
\text { Warranty checking } \\
\text { Loan service }\end{array}$ & $\begin{array}{l}\mathrm{X} \\
\mathrm{X} \\
\mathrm{X} \\
\mathrm{X} \\
\mathrm{X} \\
\mathrm{X} \\
\mathrm{X} \\
\mathrm{X} \\
\mathrm{X} \\
\mathrm{X} \\
\mathrm{X} \\
\mathrm{X}\end{array}$ & $\begin{array}{l}X \\
X \\
X \\
X \\
X\end{array}$ & $\begin{array}{l}X \\
X \\
X \\
X \\
X \\
\end{array}$ \\
\hline
\end{tabular}


Table 5: Interface rules

\begin{tabular}{|c|c|c|}
\hline Data & Paperwork & Physical item \\
\hline $\begin{array}{l}\text { - Booking data (e.g., } \\
\text { collection request) }\end{array}$ & $\begin{array}{l}\text { - Sender's account number } \\
\text { - Receiver's account number } \\
\text { - Pick up address and contact details } \\
\text { - Consignee address and contact } \\
\text { details } \\
\text { - Service level } \\
\text { - Goods description } \\
\text { - General description } \\
\text { - Number of pieces } \\
\text { - Weight (per piece) } \\
\text { - Dimensions } \\
\text { - Pick-up date } \\
\text { - Signature } \\
\text { - Customs paperwork }\end{array}$ & $\begin{array}{l}\text { - Compatible with pick-up } \\
\text { and delivery vehicle } \\
\text { - Suitably packaged (e.g., } \\
\text { stackable) } \\
\text { - Undamaged } \\
\text { - All necessary labels } \\
\text { correctly applied (e.g., } \\
\text { dangerous goods, heavy } \\
\text { item, fragile, special } \\
\text { services) } \\
\text { - Consignment number } \\
\text { written on all pieces }\end{array}$ \\
\hline
\end{tabular}


Figure 1: a generic model of modularity

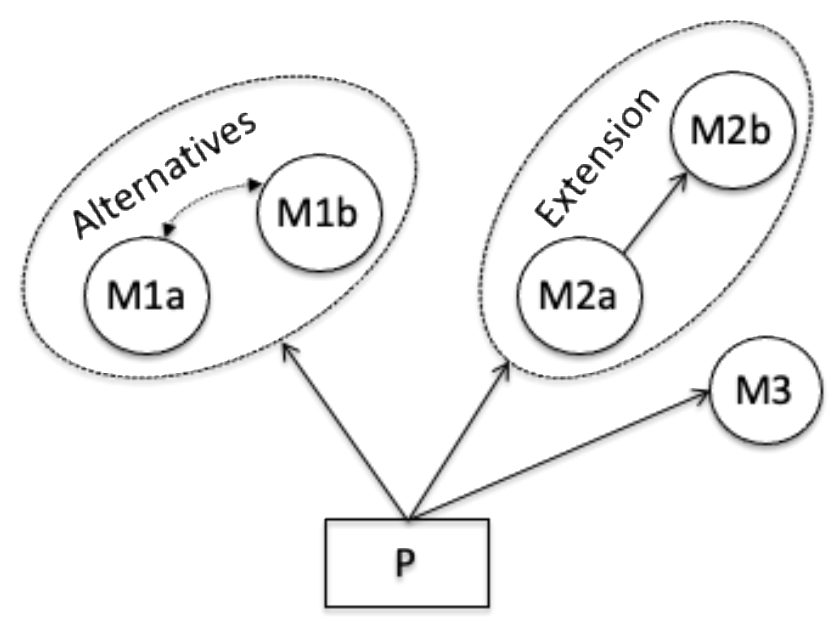




\section{Figure 2: Conceptual model of service modularitv}

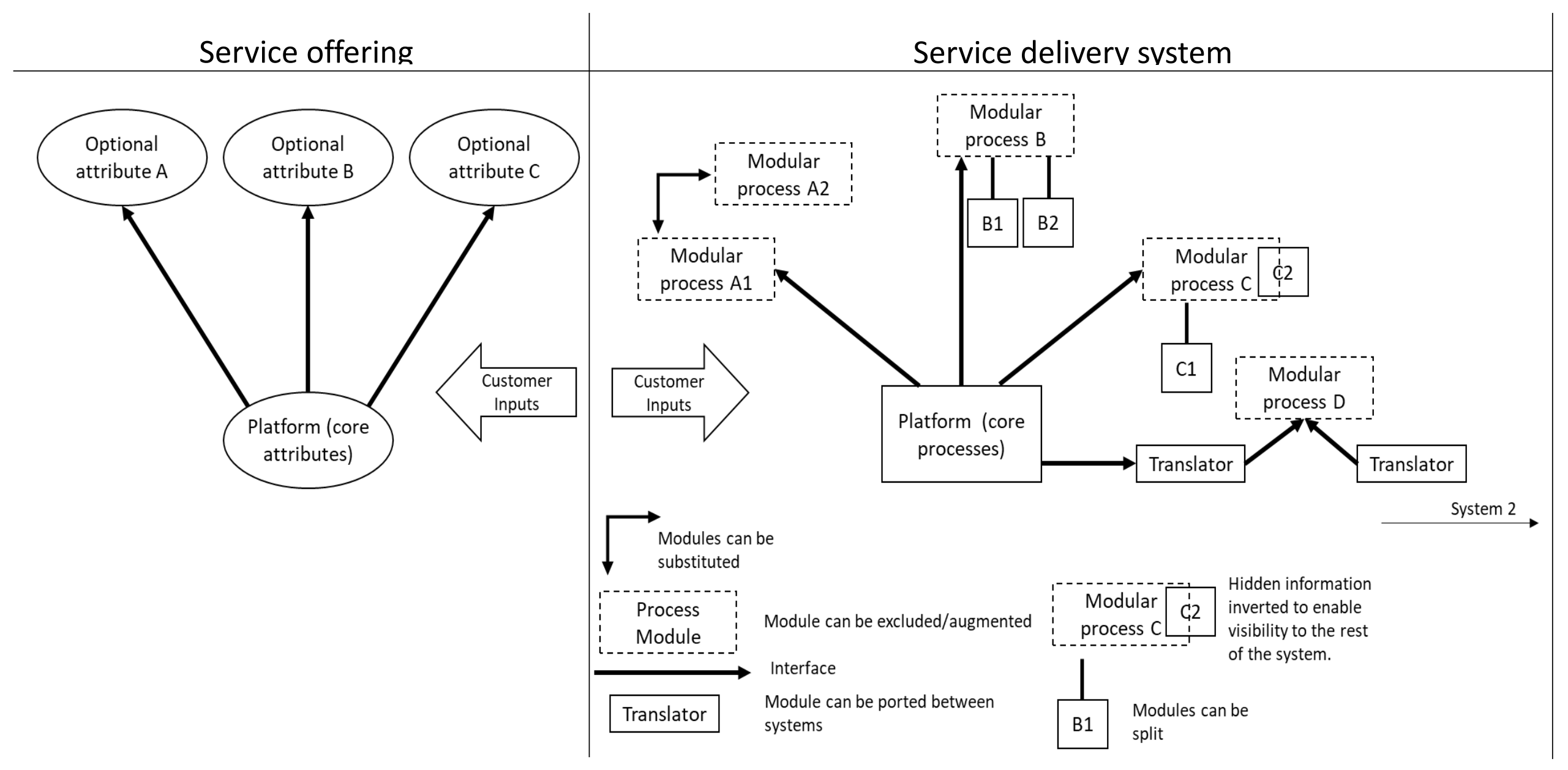




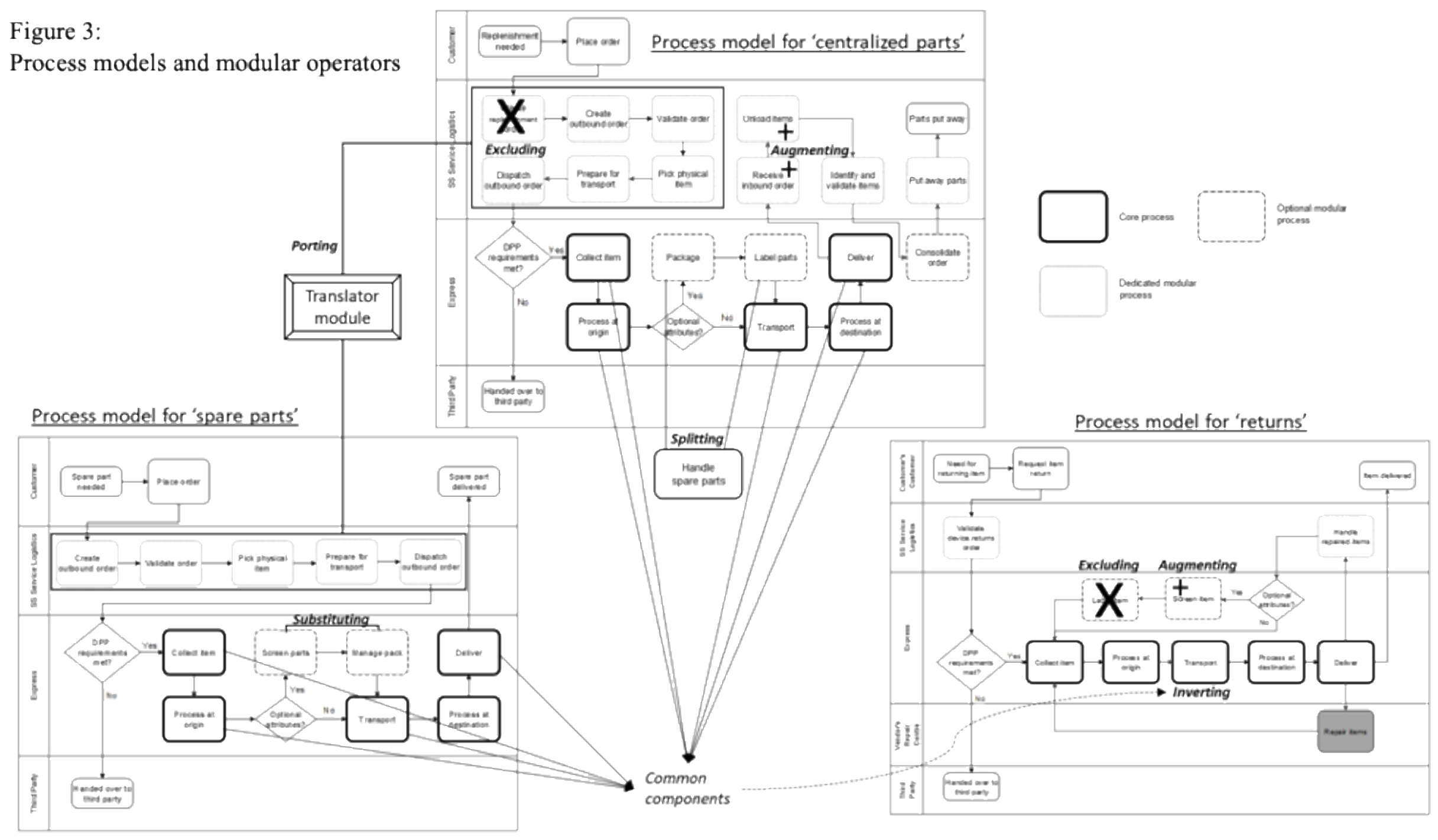




\section{Figure 4: Conceptual model of a service delivery system supporting modular service logistics offerings}

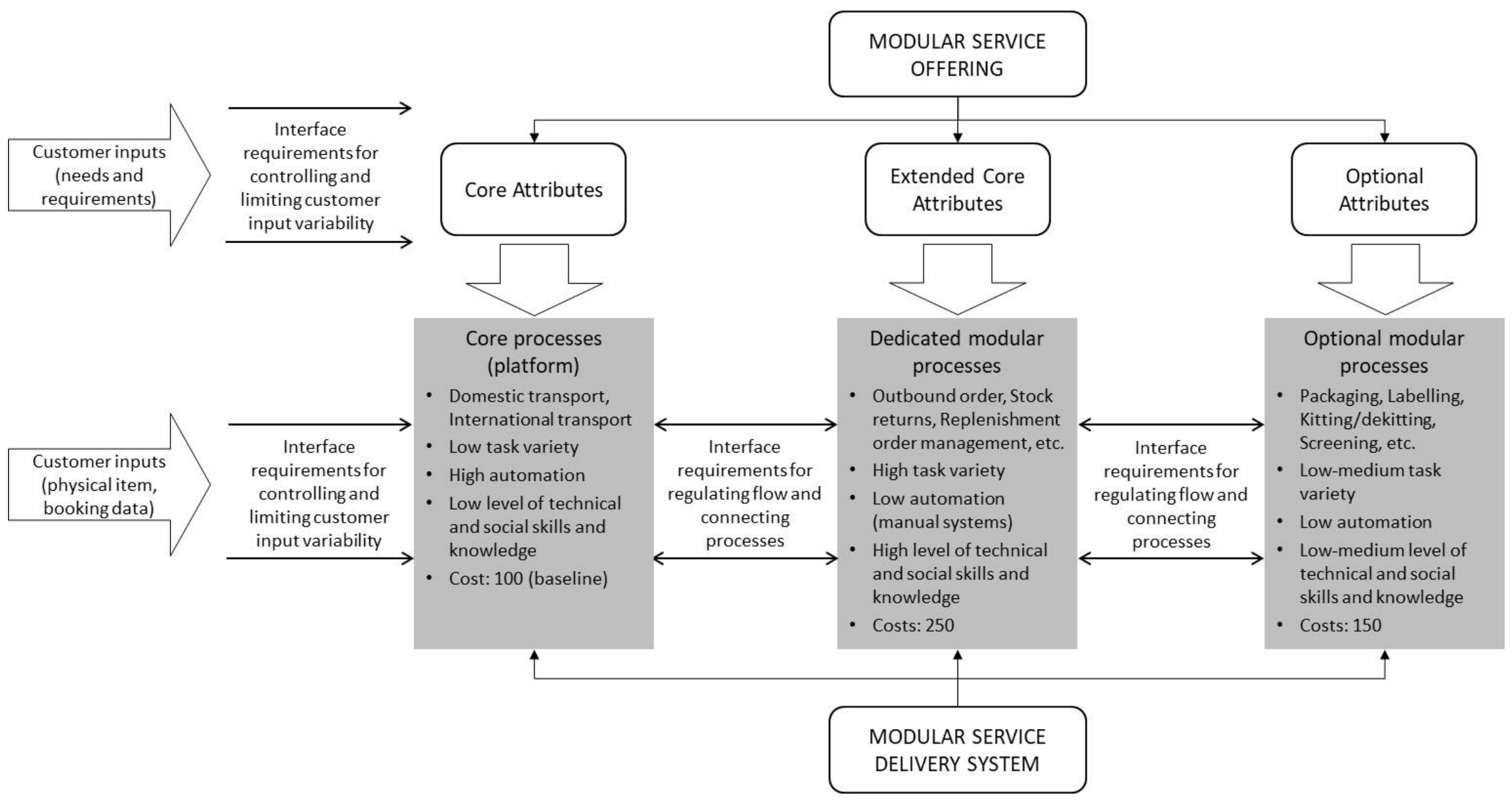




\section{Web Appendix}

Case Study Protocol

This protocol describes the field procedures to be followed. During the first visit at the company, the researchers should try to identify relevant key informants that possess a wealth of knowledge in the areas investigated in the study. In that respect, the help of the project champion should be highly valuable. Semi-structured interviews should be conducted with the key informants to address the research areas. Other, multiple sources of information such as process documentation (process maps, policies, procedures etc.), marketing information (customer data, product information etc.), and human resources information (job families, organizational charts, employee data, etc.) for instance should be investigated. These may be available from the company's internal networks (e.g. Intranet, Shared Folders), or provided by interviewees or by the Project Champion on request of the researchers. A case report should be produced shortly after data has been analyzed. The report should be sent to the Process Champion in order to receive feedback about the validity and reliability of the findings.

In order to address the research questions and explore the research issues, the researcher should collect data in two major areas: Service offerings; Service delivery system. The next sections specify in more or less detail what data should be captured and how data should be collected.

\section{A. Service offerings}

\begin{tabular}{|c|c|}
\hline Research area & Key issues and questions to address \\
\hline $\begin{array}{l}\text { Business } \\
\text { environment }\end{array}$ & $\begin{array}{l}\text { Background information } \\
\text { - Market the company competes in } \\
\text { - Key characteristics and figures: industry, share in economy, market growth, } \\
\text { market shares, growth drivers; recent evolution and future prospects }\end{array}$ \\
\hline Target Market & $\begin{array}{l}\text { Background information } \\
\text { - Target markets: who are the right customers, drivers of customer } \\
\text { segmentation, important attributes of the segment, size of the segment, sales } \\
\text { channels used by targeted segment }\end{array}$ \\
\hline $\begin{array}{l}\text { Customer } \\
\text { requirements }\end{array}$ & $\begin{array}{l}\text { Type of and variety in customer requirements (within and across service offerings) } \\
\text { - Could you provide detailed examples of what customer requirements can be? } \\
\text { - To what extent are customer requirements unique or similar? }\end{array}$ \\
\hline Service offering & $\begin{array}{l}\text { Identification, definition and description of the modular service offerings } \\
\text { - What is the offering or solution that is proposed to customers? } \\
\text { - What make the offering modular? What does modular mean in this context? } \\
\text { - What is the customer's problem that the offerings are designed to solve? } \\
\text { - What benefits and/or results provide the service offerings to customers? }\end{array}$ \\
\hline $\begin{array}{l}\text { Attributes and } \\
\text { configurations of } \\
\text { the service } \\
\text { offerings }\end{array}$ & $\begin{array}{l}\text { The type and number of attributes and options available to the customer for } \\
\text { selection (for each offering). } \\
\text { - What are the attributes that compose the service offering? } \\
\text { - Are those attributes similar or different? In what way? } \\
\text { - What options can the customer select from? How can customers mix and } \\
\text { match attributes? } \\
\text { - What options have most impact on the processes of service delivery? } \\
\text { - What are the similarities and differences in available attributes across the } \\
\text { service offerings? }\end{array}$ \\
\hline
\end{tabular}




\section{B. Service Delivery System}

\begin{tabular}{|c|c|}
\hline Research areas & Key issues and questions to address \\
\hline $\begin{array}{l}\text { Process } \\
\text { architecture }\end{array}$ & $\begin{array}{l}\text { Identification of the processes of the service delivery system: } \\
\text { - What are the processes involved in delivering the service offerings? } \\
\text { - What are the main flows between the processes, what are the relationships between } \\
\text { the processes that make up the operational system? }\end{array}$ \\
\hline $\begin{array}{l}\text { Process mapping } \\
\text { and description }\end{array}$ & $\begin{array}{l}\text { Detailed process information required for describing how each service } \\
\text { offering is delivered } \\
\text { - What are the key activities in each process and sub-process? } \\
\text { - What causes the process to start? } \\
\text { - What people or departments are involved in each of these steps/activities? } \\
\text { - What information systems are used? } \\
\text { - What constraints or regulations affect the process? } \\
\text { - What does the process produce (output)? } \\
\text { - Whom the output is for / where does it go? } \\
\text { - Possible issues / constraints / problems occurring within the process and } \\
\text { that prevent it to run smoothly. }\end{array}$ \\
\hline Resources & $\begin{array}{l}\text { Information about the resources that are involved in service delivery } \\
\text { - Skills and knowledge: nature and level of technical / interpersonal skills } \\
\text { and knowledge of employees } \\
\text { - Empowerment: extent to which an employee can exercise judgment in the } \\
\text { process of creating and delivering the service } \\
\text { - Automation / equipment: technology resources used to support or execute } \\
\text { service delivery } \\
\text { - Facility location and distribution }\end{array}$ \\
\hline Customer inputs & $\begin{array}{l}\text { Information about the inputs that customers supply into the service delivery } \\
\text { system: } \\
\text { - Nature, volume (e.g. number of transactions or items), and variety (i.e. the } \\
\text { extent to which customers provide different inputs) of customer inputs } \\
\text { - Goal: to limit or to accommodate customer input variability? } \\
\text { - How customer input variability is measured, reduced and/or } \\
\text { accommodated? } \\
\text { - Nature and frequencies of unacceptable customer inputs }\end{array}$ \\
\hline Module & $\begin{array}{l}\text { - What makes the system modular? } \\
\text { - What do you mean by modules? }\end{array}$ \\
\hline Platform & $\begin{array}{l}\text { - What do you consider to be the platform and why? } \\
\text { - What is the role of the platform? } \\
\text { - How does the platform operate? }\end{array}$ \\
\hline Interface & - What are interfaces in this context? \\
\hline
\end{tabular}




\begin{tabular}{|l|l|}
\hline & - What is the role of interfaces? \\
- What are the linkages that connect modules together? \\
- What rules dictate what and how modules are connected?
\end{tabular}

Coding framework

Table A1: Coding framework

\begin{tabular}{|c|c|c|}
\hline Research areas & Theory-informed categories & Data-informed categories \\
\hline \multirow[t]{3}{*}{ Service offering } & Type of offering & $\begin{array}{l}\text { Service parts } \\
\text { Centralized parts } \\
\text { Returns }\end{array}$ \\
\hline & Type and name of attributes & $\begin{array}{l}\text { Core attributes } \\
\text { Extended core attributes } \\
\text { Optional attributes }\end{array}$ \\
\hline & Customer inputs & Customer requirements \\
\hline \multirow[t]{4}{*}{ Service delivery system } & $\begin{array}{l}\text { Operational processes (i.e., } \\
\text { collection of tasks and } \\
\text { activities) }\end{array}$ & $\begin{array}{l}\text { Core processes } \\
\text { Dedicated processes } \\
\text { Optional processes }\end{array}$ \\
\hline & $\begin{array}{l}\text { Tangible and intangible } \\
\text { resources }\end{array}$ & $\begin{array}{l}\text { Shared versus specific/dedicated } \\
\text { resources } \\
\text { Employee characteristics (skills and } \\
\text { knowledge) } \\
\text { IT systems characteristics } \\
\text { Equipment and facility characteristics } \\
\text { Costs }\end{array}$ \\
\hline & Interfaces & $\begin{array}{l}\text { Acceptance/rejection of customer } \\
\text { requirements } \\
\text { Regulation/control of flow }\end{array}$ \\
\hline & Customer inputs & $\begin{array}{l}\text { Physical items } \\
\text { Customer (booking) data }\end{array}$ \\
\hline
\end{tabular}

